\title{
DISCUSIÓN DEL EROS EN PARADISO
}

\author{
Roberto Echavarren \\ New York University \\ robertvarren@gmail.com
}

\section{INTRODUCCIÓN}

En 1895, año del proceso y condena de Oscar Wilde, se publicó, aparentemente sin problemas con la censura, la primera novela homoerótica del Brasil: O bom crioulo. El autor, Adolfo Caminha, había servido en la Marina y la historia que cuenta, probablemente, se basa en algún hecho que le tocó de cerca o que conoció "desde dentro" en sus días de servicio.

Un crimen de pasión: un gigantesco, musculoso marino negro, a quien todos temen cuando borracho, se hace amigo de un rubio grumete de quince años del estado sureño de Santa Catarina. En 1878, Jules Verne había publicado Un capitán de quince años, cuyo protagonista enfrenta con responsabilidad y coraje grandes peligros en el África, acompañado de un fiel amigo negro de porte inmenso llamado Hércules. En la novela de Caminha el negro apodado "Bom Crioulo" se enamora de Alexis, el grumete claro adolescente. El barco donde trabajan fondea en el puerto de Río de Janeiro y ellos se trasladan a una pensión donde viven en connubio durante un año.

Aprecio ese naturalismo brasilero más que a Emilio Zola. Descripciones atrevidas, atención al detalle y a la figura justa, un espíritu de investigación, el impulso de examinar cuestiones que no habían sido tratadas antes, por parte de un escritor letrado, frecuentador de la poesía parnasiana y dueño de una perspectiva docta, allegado a las ciencias sociales y a la biología. En la novela, los dos personajes, unidos por una pasión carnal y por una amistad tierna, están vistos a la vez desde dentro y desde fuera; la voz narrativa simpatiza con sus fantasías y emociones, y a la vez diseña el territorio donde este affaire es posible: Río de Janeiro, una ciudad semi-tropical, asiento del gobierno, refinada, tolerante con los placeres. La pederastia allí no es una rareza, no da lugar a medidas represivas particulares.

Resulta conmovedora la integridad del amor de Bom Crioulo por su jovencito; lejos de ser presentado como vicioso o libertino, el negro descubre el amor por primera vez y se entrega de cuerpo y alma. El joven grumete, después de un tiempo, no puede corresponderle. Bom Crioulo descubre su traición y lo mata. 
Una obra tan franca acerca de este asunto resultaba impensable en la América hispana de entonces, igual que en Europa. En Rusia, solo después de la revolución de 1905, al aflojarse la censura zarista, se publicó una novela de contenido abiertamente homoerótico: Alas (1906), de Mijail Kuzmin. Cabe señalar que este período de tolerancia se clausuró con la dictadura bolchevique a partir de octubre de 1917.

El segundo hito de una narrativa homoerótica o de un eros "anómalo", en Brasil, es Grande Sertão, Veredas (1956), de João Guimarães Rosa. Según Antonio Cándido, allí culmina el proceso personalísimo de invención de una lengua literaria, elaborada a partir de lo peculiar de una región; la novela se destaca por un conjunto de cualidades, que la transforman en uno de los mayores logros de la lengua portuguesa:

Grande Sertão: Veredas es un largo monólogo de seiscientas páginas, sin divisiones, en que un viejo hacendado, antiguo bandido y jefe de cuadrilla narra su vida de caballería sertanista. El problema central es el de la opción ética, en los límites del bien y del mal, simbolizada por el pacto con el demonio. Durante todo el tiempo, la atracción equívoca por un compañero de armas (...) mantiene la oscilación moral, la ambigüedad, la relatividad de las fronteras (99).

Después de mencionar estas dos obras fundadoras, voy a detenerme en la narrativa de un contemporáneo hispanoamericano de Guimarães Rosa: José Lezama Lima. Su novela Paradiso (1966) tuvo problemas con la censura en el momento de su aparición en Cuba, donde ya habían instalado campos de trabajo forzado para homosexuales y otros indeseables.

\section{JOSÉ CEMÍ Y SUS DOS AMIGOS}

El capítulo IX de Paradiso presenta al protagonista, José Cemí, en conversación con sus dos mejores amigos, Fronesis y Foción. De pronto, a través de patios y corredores de la universidad se propaga un rumor escandaloso: dos atletas remeros, sorprendidos en pleno acto de sodomía por un testigo, fueron denunciados y expulsados de la institución. Los sorprendidos en pleno coito son Baena Albornoz, capitán de remeros de la universidad, penetrado por uno de los miembros de su equipo, el "novato Leregas", dueño de un glande de proporciones excepcionales. Baena Albornoz era conocido por su reciedumbre y su carácter de mataputos. Al entrar a un bar expulsaba del sitio a quienes consideraba maricones; la inspección eliminaba no solo a aquellos visiblemente amanerados, sino también a los que "tapaban" su tendencia. Baena Albornoz corresponde a una figura célebre en la literatura, a partir del personaje del Barón de Charlus de Proust: un homosexual que profesa ser hipermasculino y enemigo de los desviados, a fin de confundir cualquier rumor acerca de su persona.

Paradiso describe el ayuntamiento con una metáfora geográfica extraída del comienzo de Viaje al centro de la tierra de Jules Verne. En una de las cavidades del volcán Sneffels Jökull, en la costa occidental de Islandia, Verne, quizá bajo la impresión del extraño nombre, o de las columnas basálticas del volcán, de aspecto semejante a un inmenso pulpo, situó allí la entrada al centro terrestre. Leemos en Paradiso: "Pasó al 
sótano", donde se ocultaban los atletas para gozar, "el recuerdo del cráter de Yoculo" (397). Enclave geográfico y zona del cuerpo coinciden en una morfología equivalente: la entrada al centro de la tierra corresponde al agujero anal. Es como si la penetración estimulara una vista "en caverna" - como si una endoscopía del recto equivaliera a la inspección de una gruta de la masa terrestre-. Si, según Rimbaud, "yo es otro", ¿quién es este "yo-culo", este yo del culo? Jökull, je-cul en francés, conforma una criatura visionaria, un personaje de William Burroughs hecho de ojos y culo. Quizá el "animalcarbunclo": destila luz propia en noche cavernosa e ilumina su propio camino (según el ensayo de Lezama "Sierpe de Don Luis de Góngora").

La clarividencia es siempre conflictiva para el escritor. Aquí la excitación anal es llamada "fuego del nacimiento malo". Y alternativamente: el lugar donde se derrama un esperma estéril, como si el autor estuviera de acuerdo con la doctrina cristiana según la cual el sexo se justifica solo en aras de la reproducción. A pesar de ese supuesto reparo, la experiencia del coito anal es descrita con regodeo y culmina en el éxtasis: "un glande en extremo tenso apuntalaba un techo salpicado de gránulos de azufre, estrellas errantes y cometas, que al reventar en los acantilados producían una oscuridad que marchaba siempre como un nematelminto por la circulación linfática, hasta deshacerse en la espuma del éxtasis" (398).

El joven Leregas no se excita pensando en una mujer. Ésta no es su fantasía. Trozos de cuerpo lo excitan, fragmentos desprendidos de su calentura: "Glúteos separados de las prolongaciones cariciosas de las espaldas (...) Brazos sin relación con un rostro le apretaban como cordeles, cada cordel se trocaba en una viborilla lamiendo un poro". Esta presentación por segmentos crea ante todo dudas con respecto al sexo del cuerpo deseado, o poseído. "No, no es la rubia Gräuben" (personaje de Un viaje al centro de la tierra), se apresura a agregar Lezama. Entonces, ¿son los glúteos de quién? ¿De un hombre, de una mujer? El género se disuelve cuando una piel de goce resucita en cada uno de sus poros. Queda solo un "canal de las entrepiernas", donde opera la "columna fálica", una máquina a explosión. Se trata de un eros fuera de género, una calentura impersonal, un regodeo furioso.

Al enterarse del escándalo, Cemí y sus dos amigos no protestan la sanción que expulsa a los atletas, sin embargo, el incidente dispara un coloquio entre ellos acerca del homoerotismo. Cada uno, a su turno, expone su propio punto de vista. El formato dialógico de estos tres abordajes consecutivos evoca, no en su contenido, sino en su disposición, la serie de discursos acerca del eros en El Banquete de Platón.

\section{FRONESIS}

Fronesis es el primero en tomar la palabra. Con su curiosidad que todo lo recorre, los niños -dice- están abiertos a las posibilidades ancestrales, que ya no pertenecen al adulto. Todo está disponible para ellos, la ontogénesis recapitula la filogénesis: "El falo se hacía árbol o en la clavícula surgía un árbol" (401). Las fantasías infantiles recapitulan la memoria evolutiva de las especies, trayectos de la vida en un plano estratificado de consistencia. 
Las relaciones eróticas dejan de estar sobrecodificadas por las costumbres, dejan de ser habladas por la tradición o por las normas productivas de una sociedad histórica determinada. El niño es intempestivo, cuando no intemperante. Aún no ha descartado lo que el adulto eliminó. Se abre al impersonal espectro de una "edad de oro": "El recuerdo de esas eras fabulosas se conserva en la niñez, en la inocencia de la edad de oro, cuando es casi imposible distinguir cualquier dicotomía". La identidad y la contradicción son los polos de la máquina binaria. El niño ignora la máquina binaria que dicotomiza: u hombre o mujer, o igual (idéntico) o opuesto (y también enemigo). El niño prescinde de esta dicotomía adulta. Lo semejante no es ni lo idéntico ni lo contradictorio.

En ciertos casos, la apertura de la niñez escansiona una vida entera: "Es el tiempo de una transfiguración, es el momento en que se puede volver a habitar ese estado de inocencia". El niño camina "para ir descubriendo lo exterior, pero es lo exterior que forma parte del mismo paideuma, que es esa sustancia configurativa que permite al primitivo, al niño y al poeta ser siempre creadores". El paideuma (compuesto del griego paideia, educación, y pneuma, aire) es una noción vinculada al respirar; nombra una pedagogía de la respiración y alude a un espacio interior-exterior, una órbita de lo semejante, que engloba el aire que impele y expele. Esa órbita viva, el aire que entra y sale, el adentro y el afuera integra una "misma sustancia que es espacio y tiempo, pues señala la región del hechizo y el devenir dentro de sus contornos": "El niño (...) tiene siempre tendencia a la sexualidad semejante, es decir, a situar en el sexo (...) el otro semejante a sí mismo".

De acuerdo con Fronesis, la sensibilidad del niño, más que homoerótica, es más bien autoerótica. El niño asimila lo que se compone con él (lo semejante) mientras que lo que no se asimila, lo que no se compone, no existe para él. El niño es afirmativo, positivo, la negación no es. A partir de lo semejante, el niño y el poeta tienen la "vivencia de la divinidad, pero la palabra vivencia... está cargada de concepto, arranca de la unidad parmenídea" (402). La "unidad parmenídea", vivencia unitiva con el cosmos, el entramado de un solo animal respirando en la multiplicidad de sus expresiones, hálito intensivo que se basta a sí mismo, no tiene nada que ver con la mansa secuencia, el tiempo uniforme, el discurrir de un río: "no tiene nada que ver con ese camino que anda, como Pascal definía al río". Lo "semejante" construye, imanta un plano de consistencia, una membrana, lomo rugoso por una traza de pedrerías, de montañas, sobre cuyo perfil texturado el niño pasa un dedo. Pasa un dedo sobre cualquier cresta.

La vivencia de lo semejante alterna con la conciencia aterrada de ser un apéndice perecible del proceso cósmico: "Basta que encendamos una cerilla y la acerquemos a nuestro rostro y la luz adelanta al rostro", reflejado en un espejo, "la oscura reminiscencia de una gorgona degollada, para que tiemble como si fuese a naufragar”. El niño es el más amenazado por la necesidad, pero a la vez la pérdida de su yo en lo impersonal-semejante, su inocencia, su no-separación, lo vuelve invulnerable: "Aquel que sigue inocente toda la vida, el que más atrae la ananké, la fatalidad, es al propio tiempo el que tiene el mejor escudo para luchar contra las fuerzas destructivas de la fatalidad o de la necesidad".

Podríamos decir que para Fronesis no existe ni la homosexualidad ni la heterosexualidad. La órbita de lo semejante abarca el universo entero, en derivas no identitarias. Es una experiencia previa a las dicotomías, al error de la costumbre, que opone lo idéntico a lo no idéntico, lo idéntico a lo contradictorio. 


\section{FOCIÓN}

El segundo en intervenir es Foción. Está enamorado de su camarada Fronesis, quien lo respeta y lo quiere como un amigo, pero no le corresponde al mismo nivel. Foción se siente rechazado. Quiere forzar una unión siempre más próxima, aunque es él mismo, por paradoja, quien pone distancia entre los dos. Considera que el cuerpo de su deseo es inalcanzable, vive en la carencia. Rema siempre hacia él, pero nunca lo alcanza. Su vida emocional acentúa vicisitudes de dolorosa privación, un centro descentrado lo separa de sí. Es un sujeto dividido, amarrado al cuerpo de su deseo, pero sin poderlo alcanzar. No reside en lo próximo o lo propio - tal como el paideuma de Fronesis- sino en lo distante, en un cuerpo imposible. Perdió el eros infantil, la conformidad de lo semejante. Experimenta la ausencia, pero de hecho, según el hilo argumental de la novela, es él mismo quien determina abandonar La Habana y también a su amigo Fronesis para ir a vivir a Nueva York. O bien huir, o bien suicidarse. Su encaprichamiento, su fracaso, marcan su vida emocional. Foción vive la tendencia erótica como una condena gratuita. Algo que llega desde un vacío y no se justifica, pero lo desespera.

Él se pregunta: ¿de dónde surge la tendencia erótica? La tendencia es "un hecho que no se puede justificar, porque es más profundo que toda justificación. Toda siembra (...) se hace en el espacio sin respuesta, que al fin da respuesta. Pero es una respuesta que nos es desconocida, no tiene justificación, es un bostezo del vacío" (403). De ese fondo vacío llega cualquier cosa inesperada. El hombre, apunta Foción, tiene la capacidad de acogerla. Así sea un dragón que nos devore el seno: "lo tragicómico inesperado es que el hombre puede asimilar esa respuesta (...), pues la grandeza del hombre consiste en que puede asimilar lo que le es desconocido".

Más que justificar el homoerotismo, se pregunta Foción si la heterosexualidad no es -al fin y al cabo- un "error de la costumbre", un mal hábito que sería cuestionable mantener: "El sexo parece que tomó un camino, o se mantuvo en la costumbre de un camino que por huir del espacio vacío, se apoyó en el primer punto, los sexos, que encontró en su errancia". Los sexos, masculino y femenino -la máquina binaria, dicotómica-, ¿o más bien un número $n$ de sexos, cualquier "primer punto de apoyo"? Por hábito, la unión heterosexual, de los divididos y contrarios, se volvió una práctica preferente, en gran medida obligatoria. Pero, considerada desde la dimensión primigenia de la vida, se anula en el andrógino, o la mezcla de lo masculino o femenino, o la ausencia de ambos, que precede al dualismo: "La aparición de la mujer en el séptimo día (...) revela un estado androginal previo" (405). El andrógino es previo no solo a la diferencia de los sexos (lo que está entre las piernas) sino también, y sobre todo, a los polos que consagra la costumbre, el sistema binario de género (lo que está entre las orejas). "Todo lo que hoy nos parece desvío sexual, surge en una reminiscencia, o en algo que yo me atrevería a llamar, sin temor a ninguna pedantería, hipertelia de la inmortalidad, o sea una busca de creación (...) la creación de algo hecho por el hombre, totalmente desconocido aún por la especie. La nueva especie justificaría toda hipertelia de la inmortalidad" (406).

Foción concibe el devenir como un ir más allá de lo humano, de lo humano convencional. La grandeza de las criaturas es aceptar lo que llega de ese vacío, abrazar la tendencia y construir a partir de ella una perspectiva acerca del devenir de lo humano y de lo 
inhumano. "Algo hecho por el hombre, totalmente desconocido aún por la especie". Más allá derivan líneas de fuga: esta "hipertelia" consiste en ir más allá del telos prefijado, del programa y de la teleología. Solo la causa (la tendencia) lleva a la criatura más allá de sí, pero sin una finalidad predeterminada.

La reminiscencia remite al pasado: memoria de cosas olvidadas, que recuerda una construcción anterior. Sin embargo, Foción deriva de la reminiscencia una virtud creadora, nunca congelada, una pista para recombinar y proyectar el presente. El poder transformador atraviesa y perfora las costumbres, los arreglos consuetudinarios, las instituciones, va más allá de las formas establecidas en un momento dado para regir la conducta, la asignación de género que recibe cada cual por parte del error de la costumbre, la dicotomía prescriptiva. Por contraste, Foción ubica la vida del individuo, y también de la especie, englobada en bucles temporales más amplios, por un tiempo sideral, envolvente, que invoca nuestra máxima capacidad de apertura, un más allá sin finalidad predeterminada, ante una impensable propuesta de hipervida.

Héroe preferido de Foción es el Conde de Villamediana: "Villamediana enamorando a la esposa del rey, raptando a su sobrina, escandalizando en las corridas de toros, jugando a lo tahúr y despilfarrando el dinero en caballos y piedras preciosas, haciendo burlas con sus costumbres secretas y sus amigos clandestinos, fue una energía diabólica utilizada contra la monarquía decadente" (410). Villamediana fue una "energía diabólica" porque mezclaba lo que estaba separado, destruía el orden teológico y moral, las estructuras jurídicas de parentesco y género. El rey lo mandó matar, un sicario lo atravesó de un flechazo, "mostrando en su costado tal agujero sanguinolento de ballesta, que aún en un toro diera horror, como dijera con espanto Góngora al huir alucinado de la corte". Y Foción concluye: "Este hechizado se destruye para destruir". Villamediana es un Don Juan que ha escapado a los infiernos, porque, más allá de su muerte, "continúa escapándose con un cuerpo sin sexo". Un cuerpo sin sexo, no marcado, ni masculino ni femenino, un cuerpo que resiste a la máquina binaria, que no se deja dicotomizar. Sin sexo, sin género, o con $n$ sexos y sin la marca del género. Un erotismo sin asignación de género. Es un rebelde desconstructor del sistema binario.

A la pregunta acerca de dónde viene el eros o la tendencia que le toca a cada uno, Foción responde: no viene de ninguna parte, viene del vacío, no hay motivo, no hay origen; las tendencias vienen de un vacío que nos obliga a aceptar eso que sentimos o deseamos, sin que se nos diera parte en la elección. Por lo tanto no hay nada que justificar. Fronesis, que interrumpe aquí a Foción, pregunta: ¿qué es desvío?, ¿qué es homosexual? Se responde a sí mismo: imposible fijar límites y fronteras, por el modo en que se mezclan de hecho en cada uno de nosotros las incongruencias del comportamiento de género. Nadie es un "puro" hombre; nadie es un perfecto actor; en el momento menos pensado, la supuesta criatura viril, la supuesta identidad de hombre, muestra requiebros de puta o de damisela.

En consecuencia, Fronesis descubre el homoerotismo en todas partes; un carbonero recio mete el pie en el agua fría y lanza un ay aniñado, sin hablar de las perversiones de los llamados heterosexuales, de los modos de excitación fetichista y anal de hombres que distan de fungir ante la mujer en el rol activo programado que se espera de ellos. Casi todos se mecen en una hamaca, son y no son heterosexuales, "todos aquejados por un desvío, aunque no se pudiera señalar en relación con qué centro se verificaba ese desvío" 
(414). Resultan, en cada caso, en uno y otro detalle, que puede ser minúsculo, "tránsfugas de su costumbre vital", de la identidad de género que les fue adjudicada. Consideremos a Julio César - propone Fronesis- a modo de contraejemplo del que ha traído arriba Foción (Villamediana): a César solo le preocupaba su destino imperial. No le hacía mella que sus conciudadanos, en vista de sus prácticas sexuales, le adjudicaran el rol de hombre o de mujer; eso lo dejaba indiferente. Él sabía que era ambos, o ninguno, y se comportaba en cada caso como mejor le parecía: "Es tan extensa la cantidad de sensaciones que se ocultan detrás del rostro o la máscara de la palabra homosexual, que comprende desde los aquejados por un innegable desvío (...) hasta hombres (...) que se erizan o retuercen (...) recibiendo, con el chapuzón de las aguas, la investidura de su espíritu maternal" (415).

Cada cual tiene comportamientos, gestos, actitudes, que bien pudieran ser descritos como incoherentes con respecto a su rol asignado. En vez de clasificar a la gente a través de una letanía de identidades forzosas, más valdría considerar cómo se despliega en concreto cada cual, cómo se desenvuelve el dromenon, o "medida que respira". Esa medida, esa pauta, es un conjunto de prácticas, es "el hecho realizado", para los griegos un teorema, una conversación desenvuelta como un baile, la carretera donde los cuerpos hermosos van impulsados por la luz. "El dromenon era el espacio (...), una medida que respiraba" (415-416). Cada ser al devenir libre, con sus líneas de deriva, baila y respira, practica alegre sus poderes.

Porque "en realidad el laberinto corporal es la única forma de aprehensión de ese espacio ocupado totalmente por ese neuma o hálito universal" (417). Un espacio errante, un viento, es aliento hispostasiado en el laberinto corporal que recorre y atraviesa. Hálito innumerable, inapresable, inasible: a) "El cuerpo es la permanencia de un oleaje innumerable" (416); b) "en cada hombre esa imagen repta con mutaciones casi inapresables"; c) "pero ese inasible tiene la medida de su sexualidad".

¿Cómo apresar un eros que puede ser deleite en cada milímetro del cuerpo? ¿Cómo definirlo? Ese placer no tiene nombre. Tiene una medida, un idiolecto en cada uno, un estilo, una intensidad. El oleaje innumerable, traslúcido, de los simulacros que atraviesan el cuerpo se acumula contra un borde de mutaciones "casi inapresables", pero el "inasible" tiene una medida: no la sexualidad consuetudinaria, el error, sino la medida cabal: una versión de estilo.

Para pensar el eros -según Fronesis- tenemos que tomar en cuenta antes que nada los pulmones y el intestino. Respirar y digerir. Aparentemente los órganos de la reproducción no son "primeros" para él. Tienen además otro competidor: el cráter "Yoculo", "el orificio interior del tubo intestinal" que, de acuerdo a Las leyes de Manú que él cita, es un "órgano de la acción" y no de la mera pasividad. En consecuencia, Fronesis declara que no se considera capacitado para hablar de sexo, y mucho menos de identidades de género.

\section{JOSÉ CEMÍ}

Cede el turno al tercero de los amigos, José Cemí. Éste aborda el eros a partir de la tradición cristiana de los Padres de la Iglesia que ensalzan la castidad y procuran neutralizar el placer. Prohíben cualquier conducta que se desvíe del único fin legítimo 
de la reproducción. El coito debe ser un acto lo más neutro posible en lo que respecta al placer, correcto sólo bajo condiciones apropiadas, dentro del marco del matrimonio. Cemí examina etapas contrastadas de la reflexión cristiana acerca del sexo: San Agustín y Santo Tomás de Aquino.

Después de haber vivido una juventud pagana ardiente, apasionado de su amigo Alipio, Agustín de Hipona resuelve repudiar su vida pasada, como si fuera un período apenas, no la condición de la vida entera. Repudia lo que amó y considera que los pecados de la lujuria homoerótica son los peores. A esta posición tajante de alguien que fue, al menos en su juventud, atormentado por eros, José Cemí opone el juicio que la misma infatuación (el acto contra natura) merece a Santo Tomás de Aquino: a él no lo tentaba la lujuria. Un buey que piensa, pura castidad. "Le fue otorgado el don de los ángeles en el sexo, disfrutó de una regalada castidad en la gracia” (427).

El deseo de Tomás de Aquino está involucrado en su vida intelectual. A él le apetecen palabras y nociones, pero sin embargo su pensamiento teológico filosófico -según Cemíno pierde la conexión con los sentidos. La reflexión cristiana no puede ser sino una postrimería -acerca de otra vida después de la muerte-; Tomás vuelca su expectativa en el cumplimiento de la contemplación divina en un paraíso postemporal al cual se remite toda verdadera gloria y toda verdadera práctica; solo allí ocurrirá el gozo en acto. Los sentidos serán restaurados el día de la resurrección. Los cuerpos resucitarán perfectos para una plena vida en la gracia. En el paraíso de Santo Tomás se vuelcan, para Cemí, “apetito, posesión, y delectación frutal". Para Santo Tomás los genitales no son los órganos primeros. Para él prima la posesión y delectación gustativa, un acicate del paladar para su pensamiento. Se alimenta y escribe. Vale decir, su idea de un paraíso futuro está nutrida por los alimentos terrestres que lo engordaban día por día. José Cemí rescata el banquete de los sentidos para la fiesta del intelecto. No en vano esta novela se llama Paradiso.

El pecado nefando era la menor de las preocupaciones para Santo Tomás. Por eso, tal vez, lo juzga con menos severidad. Para él, los peores pecados son los que incluyen malicia, el propósito deliberado de hacer daño. Entre los pecados de lujuria nombra como más graves el adulterio, el estupro, el sacrilegio, el rapto. Son más graves que el pecado contra natura, porque contrarían el sentir de otro, o abusan con daño de la víctima. Pero si no se quiere hacer mal al prójimo, si no se le hace daño, entonces cabe al menos más caridad con el pecado contra natura.

No obstante, según Tomás (siguiendo la doctrina eclesiástica, que justifica el sexo solo en aras de la reproducción), la posesión por culo está mal, tanto a macho como a hembra. ¿Con qué puede compararse? Tomás la asimila a otro pecado contra natura: fornicar con las bestias. Si la moral cristiana cierra los caminos de eros, aquí, al menos, parece levantarse la barrera, al expulsar al pecador fuera del mundo de los hombres y confinarlo entre los animales. Se anula la barrera de la moral, ya que las bestias carecen de ella. En este punto, Foción interrumpe a Cemí. ¿Qué especie de pecado es éste, contra natura? ¿Lo que hacen las bestias? Pero las bestias, según el dogma teológico cristiano, no pecan. Solo los hombres pecan y son pasibles de culpa. Al devenir animales, estos individuos quedan libres de pecado: "si es bestialismo (...), y las bestias no pueden pecar, no es pecado en el hombre bestia que lo comete" (428). Por lo tanto será una bestia el homosexual, pero no un pecador. 
José Cemí responde: en efecto, si los homosexuales son bestias, es que Santo Tomás no piensa admitirlos en el paraíso con ese estigma anómalo. Si son bestias, no resucitan. Alude a otro caso controvertible concerniente a la noción de cuerpo perfecto para el aquinatense. Se trata de los eunucos. Si el cuerpo resucita íntegro, "es plausible pensar -agrega Cemí- que los eunucos serán retocados, enderezados y mejorados de voz" (429). Esta consideración irónica hilarante parece desbarrancar el razonamiento de Santo Tomás. ¿Cuál es el cuerpo perfecto? ¿El que tiene los genitales intactos? ¿Se restituirán el pene y los testículos a todos los eunucos para que se los calcen de nuevo en el paraíso? Y ¿qué pasará (podríamos agregar) con los transexuales?

Hasta avanzado el siglo XIX, para conservar su voz infantil, los papas castraban a los niños del coro Vaticano. ¿Qué mantendrán en el paraíso los coristas, los testículos arrancados o la voz angelical? Estas aporías dejan al pobre Santo Tomás turulato. Según Cemí: "Declaró que sus luces no le permitían ver claro en ese misterio" (428). Foción termina afirmando: me divirtió tu presentación de un Santo Tomás acorralado en contradicciones y absurdos, y por lo tanto "heterodoxo".

El diálogo de los tres amigos acerca del eros buscó soslayar la máquina binaria, apartar el error de la costumbre, invocar un eros primigenio de lo semejante. Se abrió al paideuma, la respiración cósmica, prolongada en el dromenon, poder de "hecho realizado": práctica, teorema ambulante, baile. Siendo un individuo de respiración difícil, Lezama recurre a la expansión mágica de los polvos para el asma con que fumigaba su habitación, marca Abisinia Exibar. Era su droga de predilección, junto con el habano. A partir de esos estímulos desataba coreografías.

\section{HOMBRE-DIOS}

La conversación acerca del homoerotismo se disparó a partir de un hecho escandaloso: el coito entre dos atletas; luego, se ve interrumpida por otro coito, pero esta vez entre un hombre y una mujer. En el capítulo IX se ve cómo Fronesis es obligado por su amiga Lucía a abandonar la conversación, luego, en el capítulo X, sabemos que Fronesis solo logra poseerla mediante el truco de tapar su vagina con una camiseta, proyectando sobre la superficie blanca de la tela, a modo de una pantalla de cine, su propia fantasía de lo semejante, capaz de excitarlo: recrea a un "hombre-dios" construido con notable detalle y exótico diseño. La vagina en primer lugar le espanta. Ve en esa repugnante, temible y desagradable zona un terreno tajeado, zanjas de negra y hostil vegetación, muy lejos del jardín ameno, "un yerbazal picoteado" (433), "una estribación retorcida", "un terreno carbonífero", "un informe rostro fetal, deshecho, lleno de cortadas, de costurones" (451). Todo lo cual, no puede evitarlo, le provoca "náuseas". Ante panorama tan tétrico, teme volverse impotente. Entonces inventa un truco: se quita su camiseta blanca, recorta un círculo y en el medio del círculo abre un agujero. Pone el trapo sobre el vientre de Lucía, y sin tener que ver ni vientre ni vagina, fantasea sobre esa pantalla de proyección, libre, mientras copula, un "hombre-dios" hecho de partes relumbrantes. Su atractivo no es común. No es un hombre, es el andrógino, no marcado por el género. El "hombre- 
dios", la fantasía de Fronesis, fetiche inmanente de su eros, está revestido de un poder que emana del atuendo y la figura. Es el fetiche que Fronesis necesita para excitarse y copular dentro de un vientre escalofriante recubierto:

El hombre dios tenía las orejas trabajadas en mosaicos azules, tenía un collar de oro con espaciosidades de caracoles corroídos por el salitre yodado, reverso en los olores de la canela. Las espaldas con unas correas donde parecía que corrían unos ratones en llamas. Las rodillas traía envueltas en el moteado del tigre, donde colgaban caracoles con olores difíciles (...) La mitra que usaba tenía alteraciones moteadas, o jaspe de tigre. La cara de negruras y todo el cuerpo de un ébano puntiagudo. Una sobrepelliz muy ondulada de ornamentos le caía sobre la espalda y los pectorales, marcándole la glútea y la vulva verdosa (462).

Imagen glam abigarrada, espacio construido de adornos y de olores, no es fijo, sino mercurial; tiene la vulva en el culo, vulva anal del glúteo: "marcándole la glútea y la vulva verdosa”. Estamos de nuevo ante Yoculo, aquel volcán islandés. Las úes hollan la hundida entrada. Éste es el eros de lo semejante para Fronesis. Su "cuerpo" no es humano (no es su amigo Foción, por ejemplo) sino hipertélico, impersonal, una prótesis que rebasa cualquier identidad de hombre o de mujer. El "hombre dios" es una simbiosis, un ensamblaje imantado, toque divino y animal de un conglomerado o enjambre, prodigio donde luchan los atributos de una sustancia única, espumosa de mar y de "olores difíciles". Es una reanimación de los sentidos, una imagen-devenir, a través de estimulantes territorios y fronteras. "Para reanimar los huesos en el infierno", para eso "el hombre dios silbó en los aires barrenderos, para retrotraer la lluvia a los caminos del viento". El hombre-dios está hecho de devenires intensos: animales (ratones, caracoles, tigres), etnias (devenir negro), sexos (tiene glande puntiagudo y vulva), elementos (tierra, mar), exhala olores marinos sin perder la compañía terrestre de la canela. Es un acontecimiento de intensidades reales, un concomitante del coito de Fronesis. Deviene animal, deviene inorgánico (brillo, salitre, yodo), deviene otra raza, otro sexo, cualidades intensivas que encienden, acompañan el follar, que nutren un plano de consistencia. Por fin la eyaculación de Fronesis hace que el "hombre dios" vuelva a caer en la nada, en el vacío del que emergió anillado, para penetrar "la imagen de la imagen"; y reencuentra el "bostezo" del vacío.

\section{BIBLIOGRAFÍA}

Cándido, Antonio. Introducción a la literatura de Brasil. Caracas: Monte Ávila, 1968.

Lezama Lima, José. Paradiso. Ed. Eloísa Lezama Lima. Madrid: Cátedra, 2010. 